Institute of $\mathbf{F}_{\text {ood and }} \mathbf{A}_{\text {gricultural }} \mathbf{S}_{\text {ciences }}$

\title{
Manual de los Reglamentos del Agua de Florida: Plaguicidas ${ }^{1}$
}

\author{
Michael T. Olexa, Laura Minton, Dulcy Miller, y Sarah Corbett ${ }^{2}$
}

\section{Agradecimientos}

Los autores agradecen a Richard Budell de la Oficina de Política del Agua Agrícola del Departamento de Agricultura y Servicios al Consumidor de Florida. Los autores también agradecen a David H. Hammonds, Consultor del Programa de Salud Ambiental, Oficina de Programas de Aguas de Drenaje en el Sitio, del Departamento de Salud de Florida, y a Edward A. Bettinger, Consultor del Programa de Salud Ambiental, Oficina de Programas de Agua del Departamento de Salud de Florida.

\section{¿Quien Regula los Plaguicidas?}

El uso de los plaguicidas cae dentro del limite de varios estatutos federales así como de la ley de Florida. Bajo la ley federal, los plaguicidas son primariamente regulados por el Acta Federal de Insecticidas, Fungicidas y Rodenticidas (AFIFR). Muchos otros estatutos federales y agencias aparecen en el juego, aun en muchas situaciones particulares. Florida ha promulgado una legislación adicional diseñada específicamente para cubrir el uso de los plaguicidas, con el cumplimiento primario de la autoridad, establecida en el Departamento de Agricultura y Servicio al Consumidor (DASC) de Florida. La mayoría de esas leyes y regulaciones son similares a aquellas establecidas por el gobierno federal. Cada plaguicida distribuido, vendido o en

1. Este es el documento EDIS FE088, una publicación del Department of Food and Resource Economics, Florida Cooperative Extension Service, Institute of Food and Agricultural Sciences, University of Florida, Gainesville, FL. Publicada Noviembre 2002. Por favor visite la página electrónica EDIS en http://edis.ifas.ufl.edu.

2. Michael T. Olexa, es profesor del Department of Food and Resource Economics, Florida Cooperative Extension Service, Institute of Food and Agricultural Sciences, University of Florida, Gainesville, FL; y miembro de Florida Bar; Presidente de Agricultural Law Committee of The Florida Bar; y Director del Agricultural Law Center. Laura Minton, Dulcy Miller, y Sarah Corbett son estudiantes graduadas de Levin College of Law, University of Florida, Gainesville, FL. Filiberto Reyes-Villanueva fue el traductor de la versión en ingles al español.

Esta publicación esta diseñada para proporcionar información precisa, actualizada y autorizada sobre esta material. Sin embargo, ya que las leyes, reglas administrativas y decisiones de la corte, sobre las cuales están basados, están sujetas a revisión constante; algunas partes de esta publicación podrían ser obsoletas en cualquier momento. Esta publicación es distribuida bajo el entendimiento que los autores no están involucrados en ninguna representación legal u otros servicios profesionales, y que la información contenida aquí no debe ser considerada como un substituto de una asesoria legal. Esta publicación no esta completa en proporcionar toda la información para lograr el cumplimiento de las leyes y reglamentos que gobiernan la protección del agua. Por estas razones, el uso de estos manuales por cualquier persona constituye un acuerdo para mantener libre de daño a los autores, al Florida Cooperative Extension Service, al Institute of Food and Agricultural Sciences, y a la University of Florida por cualquier demanda por responsabilidad de daños, o gastos en que pueda incurrir cualquier persona, como un resultado de hacer referencia o confianza sobre la información contenida en esta publicación. Esta publicación fue apoyada financieramente por el Florida Department of Agriculture and Consumer Services.

El Instituto de Alimentos y Ciencias Agrícolas es Un empleador que opera bajo Acción Afirmativa y provee Oportunidades Igualitarias, dedicado a promocionar la investigación, a información educativa y otros servicios, únicamente a los individuos e instituciones que operan baj discriminación sin considerar color, raza, sexo, edad, incapacidad u origen. Para más información sobre como obtener otras publicaciones de la extensión, comuníquese con la oficina de Servicio de Extensión de su condado. Servicio de Extensión de la Florida / Instituto de Alimentos y Ciencias Agrícolas / Universidad de la Florida / Christine Taylor Waddill, Decana. 
oferta de venta dentro del estado o transportado en el comercio interestatal, así como el establecimiento pertinente u organización, debe ser registrado y renovado anualmente con la DASC.

\section{¿Porqué son Tan Importantes las Etiquetas en los Plaguicidas?}

Las etiquetas en los plaguicidas se están convirtiendo en un instrumento central para hacer cumplir tanto la AFIFR, como la ley estatal. Bajo la AFIFR, los usuarios deben satisfacer todas las instrucciones de aplicación y de precaución de las etiquetas. En este sentido la etiqueta es la ley. La falla en el cumplimiento de la etiqueta, puede resultar en estrictas penalidades. Es importante notar que le agricultor puede ser penalizado también si es un empleado del agricultor que fue responsable por la falla al seguir las instrucciones de la etiqueta.

Los estatutos de Florida eximen a los usuarios de los plaguicidas de seguir las instrucciones de etiquetas solamente para los siguientes puntos:

- el plaguicida puede ser aplicado en dosis mas bajas, y con menos frecuencia, que las recomendadas en la etiqueta.

- el plaguicida puede ser usado contra una plaga no especificada como plaga blanco por la etiqueta, mientras que la aplicación se haga en un cultivo, animal o un sitio especificado por la etiqueta, y esta no prohíbe su aplicación.

- los aplicadores pueden emplear cualquier método de aplicación no prohibido por la etiqueta.

- los aplicadores pueden mezclar el plaguicida con un fertilizante cuando no este prohibida por la etiqueta.

\section{¿Cuáles son los Plaguicidas de Uso Restringido?}

Tanto la Agencia de Protección Ambiental (APA) y el DACS de Florida, tienen clasificados todos los plaguicidas, en base a su ingrediente activo, como "plaguicidas de uso general" o "plaguicidas de uso restringido".

\section{Plaguicidas de Uso General}

Estos pueden ser aplicados por cualquiera quien siga las instrucciones y leyes adheridas.

\section{Plaguicidas de Uso Restringido}

Estos pueden ser aplicados por aplicadores con permiso o aquellos quienes trabajan bajo la supervisión directa de un aplicador con licencia. Todos los plaguicidas de uso restringido clasificados por la APA, son incorporados dentro de la lista del DASC para referencia. El DASC de Florida también ha emitido su propia lista, de tal manera que un plaguicida podría ser restringido en Florida, aun cuando este abierto al uso general, bajo las reglas de la APA.

Tanto las leyes federales como estatales proveen diferentes tipos de permisos para aplicadores de plaguicidas de uso restringido, privados y comerciales. Generalmente, los aplicadores privados están autorizados para aplicar insecticidas solamente en sus tierras. Las evaluaciones y otros requerimientos son diferentes para aplicadores privados y comerciales. La distinción es también importante en relación a las violaciones de licencias, ya que los aplicadores comerciales están sujetos a penalidades substancialmente mas severas que los aplicadores privados.

\section{¿Cuándo es Requerido un Permiso SNEDC?}

Bajo el acta federal de Aguas Limpias (como se reseña en la sección de Desechos Sólidos), cualquier contaminación de fuente de punto en una vía acuática navegable debe tener un permiso del Sistema Nacional para la Eliminación de Descargas Contaminantes (SNEDC), según la APA (ver Acta de Agua Limpia). Mientras el flujo de retorno de irrigación es eximido de su requerimiento, otras actividades contaminantes agrícolas no lo son. Por ejemplo, una zanja conteniendo fertilizantes o plaguicidas que entran en vías acuáticas navegables, es una fuente de contaminación de punto, y esta sujeta a los requerimientos permisibles por el Acta de Agua Limpia. 


\section{¿Qué Hay Acerca del Agua Potable?}

Cualquier contaminante introducido a una fuente de agua para consumo humano, incluyendo pozos y acuíferos, están sujetos a regulación bajo el Acta Federal de Agua Potable Segura. Debe mencionarse que esta acta ha sido interpretada para cubrir el flujo de retorno de irrigación el cual filtra de regreso por debajo de la superficie del agua como una "inyección subterránea" si el flujo acarrea cualquier contaminante.

\section{¿Cómo Deben ser Almacenados y Distribuidos los Plaguicidas?}

EL AFIFR requiere de la adhesión a las instrucciones de la etiquetas así como se extiende para el almacenaje y distribución de los plaguicidas. Además, los plaguicidas frecuentemente caen dentro de la clasificación de (ARCR), y están usualmente sujetos a las regulaciones de distribución para los "desechos sólidos". Las secciones de la ARCR y la AFIFR de esas publicaciones deberán ser revisadas antes de almacenar y distribuir cualquier plaguicida.

La APA proporciona las reglas para el almacén y distribución de plaguicidas que, aun cuando no es obligatorio, son útiles en el proceder con sitios específicos de localización de almacenaje, protegiendo aguas subterráneas y evitar la contaminación ambiental.

\section{¿Qué son los Requerimientos Anti Sifón?}

La ley de Florida requiere que todos los sistemas de irrigación que son usados para administrar el manejo de materiales agrícolas (como plaguicidas y fertilizantes) sean equipados con un dispositivo anti-sifón para prevenir el reflujo de agua contaminada de plaguicidas o fertilizantes hacia el agua del acuífero. Esas reglas también se aplican a plaguicidas pre-mezclados con fertilizantes, aunque tales mezclas deben ser claramente etiquetadas antes que puedan ser ofrecidas a la venta. Las especificaciones para el dispositivo anti-sifón son detalladas en las reglas promulgadas por DASC.

\section{¿Cuáles son los Castigos?}

De acuerdo a los Estatutos de Florida, sección 487.175, si cualquier persona, aplicador o con permiso, viola cualquier medida de este Capitulo, el DASC puede hacer lo siguiente:

- negar una aplicación para un permiso.

- revocar o suspender un permiso.

- emitir una carta de advertencia.

- poner la licencia en prueba y requerir a quien tiene permiso tomar clases educacionales.

- imponer una cuota administrativa no excediendo de $\$ 10,000$ por cada violación.

La violación de una parte del Capitulo 487, de los Estatutos de Florida, es un delito menor de segundo grado y cualquier subsecuente violación es un delito menor de primer grado, castigable como se estipula en los Estatutos de Florida, Secciones 775.082 y 775.083 .

Hay castigos separados por violación de los estatutos federales. Cualquiera solicitante, para aplicador comercial, vendedor mayorista, revendedor, vendedor minorista u otro distribuidor, que viola con conocimiento cualquier parte del estatuto, esta sujeto a penalidades civiles de hasta $\$ 50,000$ por cada ofensa y multas penales de hasta $\$ 50,000$ y/o un año en prisión. Los aplicadores privados están sujetos a multas civiles de hasta $\$ 1,000$ por cada ofensa y castigos penales arriba de $\$ 1,000$ y/o 30 días en prisión.

\section{Fuentes}

Código 7 de los Estados Unidos secciones 136-136y; Código 40 de los Estados Unidos secciones 300f-300j-26; Código 33 de los Estados Unidos secciones 1251 a 1387; Capitulo 487, de los Estatutos de Florida; Código Administrativo 5E de Florida.

\section{Contactos de Información}

